\title{
Levantamento de atividades e fontes fixas poluidoras do ar na cidade de Balsas-MA
}

\author{
Survey of activities and stationary sources of air pollution in the city of Balsas-MA \\ Estudio de las actividades y fuentes fijas de contaminación atmosférica en la ciudad de Balsas-MA
}

Recebido: 17/08/2021 | Revisado: 25/08/2021 | Aceito: 01/12/2021 | Publicado: 11/12/2021

\author{
Marcos Vinicius Elias Martins \\ ORCID: https://orcid.org/0000-0002-5243-9416 \\ Universidade Federal do Maranhão, Brasil \\ E-mail: vfederal@hotmail.com \\ Rayssa Guimarães Rosa \\ ORCID: https://orcid.org/0000-0003-1414-6791 \\ Universidade Federal do Maranhão, Brasil \\ E-mail: rayssagrgr@gmail.com \\ Gislane Pinho de Oliveira \\ ORCID: https://orcid.org/0000-0002-0360-5617 \\ Universidade Federal do Maranhão, Brasil \\ E-mail: gislane.oliveira@ufma.br
}

\begin{abstract}
Resumo
Este trabalho apresenta um diagnóstico da poluição do ar através da quantificação e análise das características das principais fontes poluidoras da região do município de Balsas-MA, por meio do levantamento de dados acerca dos pontos referidos. O município de Balsas, localizado na região sul do estado do Maranhão, além de já ser uma região bastante conhecida pelo Agronegócio e intensificação de mecanização agrícola, passa por um processo cada vez mais crescente de industrialização. Do ponto de vista comercial, essa situação é excelente, porém do ponto de vista sanitário, toxicológico e ambiental tal situação, quando não realizada de forma correta, pode gerar danos à população e ao ecossistema da região. Diante disso, o trabalho tem como objetivo, verificar quais e quantos são os pontos de emissão de poluentes fixos que se localizam na região do município de Balsas, além de realizar uma caracterização dos possíveis poluentes que são emitidos por estes pontos. Assim, o presente trabalho mostrou que mesmo em um perfil dado como moderado, a cidade possui tendência a ter índices que podem se elevar com o tempo, por alguns motivos, tais como: falta de fiscalização por parte de órgãos ambientais; e falta de Conscientização por parte da população, que ignora todos os sinais de que os danos gerados pela emissão de poluentes não afetam apenas o meio ambiente, mas todos os seres que vivem naquele determinado meio, e isto inclui o ser humano.
\end{abstract}

Palavras-chave: Região; Balsas-MA; Levantamento; Mecanização; Poluentes; Agronegócio; Danos.

\begin{abstract}
This paper presents a diagnosis of air pollution through the quantification and analysis of the characteristics of the main pollutant sources in the region of the city of Balsas-Ma, through the survey of data about the mentioned points. The city of Balsas, located in the southern region of the state of Maranhão, besides already being a region well known for agribusiness and the intensification of agricultural mechanization, is undergoing an increasing process of industrialization. From the commercial point of view, this situation is excellent, but from the sanitary, toxicological, and environmental point of view, this situation, when not done correctly, can cause damage to the population and to the ecosystem of the region. Therefore, this work aims to verify which and how many points of emission of fixed pollutants are located in the region of the city of Balsas, besides performing a characterization of the possible pollutants that are emitted by these points. Thus, this work showed that even in a profile given as moderate, the city has a tendency to have rates that may rise over time, for some reasons, such as: lack of supervision by environmental agencies; and lack of awareness by the population, which ignores all signs that the damage generated by the emission of pollutants affects not only the environment, but all beings living in that environment, and this includes the human being.
\end{abstract}

Keywords: Region; Balsas-MA; Survey; Mechanization; Pollutants; Agribusiness; Damage.

\section{Resumen}

Este trabajo presenta un diagnóstico de la contaminación atmosférica a través de la cuantificación y el análisis de las características de las principales fuentes contaminantes en la región del municipio de Balsas-MA, mediante un estudio de datos sobre los puntos mencionados. El municipio de Balsas, situado en la región sur del estado de Maranhão, además de ser ya una región muy conocida por el agronegocio y la intensificación de la mecanización agrícola, está experimentando un creciente proceso de industrialización. Desde el punto de vista comercial, esta situación es excelente, pero desde el punto de vista sanitario, toxicológico y medioambiental, esta situación, cuando no se realiza correctamente, puede causar daños a la población y al ecosistema de la región. Por lo tanto, el trabajo tiene como 
objetivo verificar cuáles y cuántos puntos de emisión de contaminantes fijos se encuentran en la región del municipio de Balsas, además de realizar una caracterización de los posibles contaminantes que son emitidos por estos puntos. Así, este trabajo demostró que aún en un perfil dado como moderado, la ciudad tiene una tendencia a tener índices que pueden elevarse con el tiempo, por algunas razones como: la falta de supervisión por parte de los organismos ambientales; y la falta de conciencia por parte de la población, que ignora todos los indicios de que los daños generados por la emisión de contaminantes afectan no sólo al medio ambiente, sino a todos los seres que viven en ese entorno particular, y esto incluye al ser humano.

Palabras clave: Región; Balsas-MA; Encuesta; Mecanización; Contaminantes; Agroindustria; Daños.

\section{Introdução}

O número crescente da circulação de veículos no mundo e as atividades industriais são fatores que contribuem fortemente para a poluição da atmosfera (Cançado,2006). Esta pode ser originada também por fontes naturais como queima acidental de biomassa (material derivado de plantas ou animais) e erupções vulcânicas (César et al., 2013). Novas fontes de poluentes, como a queima de combustíveis fósseis pelos motores, a combustão e a expansão das indústrias siderúrgicas ganharam força com a revolução industrial e isso ocorreu sem um acompanhamento dos possíveis danos que esses poluentes poderiam causar à saúde humana (Mário, 2012).

Apesar de avanços terem surgido nas últimas décadas, em relação a práticas que proporcionem um ar mais limpo, principalmente nos países desenvolvidos, os atuais níveis de poluição atmosférica continuam a ser considerados danosos para a saúde (Gouveia, 2006).

Estudos sobre a poluição atmosférica e os efeitos na saúde da população têm demonstrado que, mesmo quando os poluentes se encontram abaixo dos níveis determinados pela legislação, estes são capazes de provocar efeitos na saúde das pessoas (Nascimento E Francisco, 2013).

Conforme CETES (2019), poluente atmosférico é toda e qualquer forma de matéria ou energia com intensidade e em quantidade, concentração, tempo ou características em desacordo com os níveis estabelecidos em legislação, e que tornem ou possam tornar o ar impróprio, nocivo ou ofensivo à saúde, inconveniente ao bem-estar público, danoso aos materiais, à fauna e à flora ou prejudicial à segurança, ao uso e gozo da propriedade e às atividades normais da comunidade.

A agricultura representa uma das principais atividades na economia brasileira, sendo um setor importante no equilíbrio da balança comercial (CEPEA/ESALQ, 2016). Ao analisar o papel da agricultura, amplia-se a perspectiva para o agronegócio, com exclusão da pecuária, estes valores chegam a alcançar 16\% do PIB e, aproximadamente, 35\% da exportação brasileira (Portal IMESC, 2019). O valor da produção agrícola nacional foi de R $\$ 265,5$ bilhões, 5,6\% a mais que 2014, somente a cultura de soja movimentou US\$ 28 bilhões em exportações ao ano (IBGE, 2016).

Na safra de 2015, a área plantada no Maranhão foi de 1.829.731 hectares, com área colhida de 1.829 .354 e o valor da produção agrícola foi de $\mathrm{R} \$ 3,8$ bilhões. Os dez maiores municípios produtores do estado produziram juntos mais de $\mathrm{R} \$ 2$ bilhões, representando 57,59\% de toda produção do Maranhão, dentre os principais: Balsas (R \$ 691,8 milhões), Tasso Fragoso (R \$ 543,6 milhões), Alto Parnaíba (R\$ 172 milhões), e Sambaíba (R\$ 171,2 milhões), com destaque a produção de soja e milho (IBGE, 2015). O importante aqui a ser destacado é o impacto que agricultura possui quando lava-se em consideração o processo realizado para produção agrícola e seus possíveis efeitos (Berni, Barjay, 1998).

Com centenas de milhares de hectares em fazendas modernas e produtivas com plantações de algodão, arroz, cana-deaçúcar, feijão, milho, soja e sorgo, a cidade de Balsas-MA destaca-se desde a década de 1990 no cenário da agricultura, principalmente na produção de soja, sendo o principal produtor do Estado (Bueno, 2001). A área plantada por hectare (ha) e as quantidades produzidas em toneladas (t) por hectare (ha), na região, para as culturas de cana-de-açúcar, milho e soja foram, respectivamente, 16ha e 363t/ha; 102442ha e 447771t/ha; e 187144ha e 505289t/ha (IBGE, 2017). 
Neste cenário, são exacerbados os índices de emissões de poluentes por plantações na cidade, desde resíduos líquidos a gases emitidos na atmosfera. Neste trabalho, as análises seguem para a produção de soja, tendo em vista que é a cultura mais cultivada na região do município.

O município de Balsas atualmente passa por um grande crescimento devido o crescimento e expansão agrícola que ocorre nesta região, isto traz consigo todos os demais problemas ambientais que surgem devido esse crescimento e entre eles está a poluição atmosférica. Deste modo, o presente trabalho tem como objetivo realizar um levantamento de fontes poluidoras no município e caracterizar os possíveis poluentes com base no ponto de emissão.

\section{Metodologia}

\subsection{Metodologia da pesquisa}

A pesquisa consiste de um levantamento quantitativo e avaliativo dos pontos de emissão de poluentes no município de Balsas/MA, para tal andamento o trabalho foi dividido nas seguintes etapas:

1- Divisão dos membros do trabalho em relação aos respectivos bairros do município, com o intuito de ter maior abrangência dos focos de emissão;

2- Contabilização dos pontos amostrados seguido da localização para que os mesmos possam ser colocados em um mapa que mostra de forma mais ampla os pontos em relação à cidade;

3- Confeccionamento de um mapa que mostra o município de Balsas com todos os pontos que foram possíveis serem avaliados;

4- Categorização e classificação quanto aos pontos referidos para que quando comparado com a literatura ao invés de ir um único ponto, seja realizado tal comparação de maneira abrangente, para todos os pontos que se encontrem dentro da mesma categoria ou sejam os mesmos (diferenciando-se, neste caso, apenas o bairro);

5- Análise da literatura, realizando uma comparação da classificação dos pontos com a literatura, para que, deste modo, seja possível estabelecer uma possível estimativa ou mediana em relação ao que foi analisado como sendo ponto de emissão de poluentes no município;

Tendo em vista os diversos processos do ciclo de produção que vão desde o preparo do solo, com adubação, plantação, aplicação de herbicidas, entre outros, até a etapa de colheita, são inúmeras as emissões de poluentes geradas. Como destaques de poluentes estão as emissões provenientes do uso de fertilizantes e as geradas pelos combustíveis dos maquinários utilizados.

No caso da cana de açúcar, durante o crescimento da cultura há emissões significativas de $\mathrm{N}_{2} \mathrm{O}$ devido às aplicações de nitrogênio como fertilizante ou de fontes orgânicas (vinhaça e tortas), constituindo $80 \%$ das emissões totais em equivalentes de $\mathrm{CO}_{2}$ nesta fase. $\mathrm{Na}$ colheita, a queima da cana é responsável por grandes emissões de $\mathrm{CH}_{4}$ e $\mathrm{N}_{2} \mathrm{O}$, que totalizam 982,3 $\mathrm{kg}$ e 195,3 $\mathrm{kg}$ de equivalentes do $\mathrm{CO}_{2}$, respectivamente, para $60 \%$ da área colhida com queima, totalizando $38 \%$ de todas as emissões de GEEs $^{1}$ no processo de produção de álcool (Bueno, 2001).

No processo de combustão do petróleo para produzir-se $1 \mathrm{GJ}$ de energia, tem-se a produção $73,3 \mathrm{~kg} \mathrm{CO}_{2}, 0,003 \mathrm{~kg} \mathrm{CH}$ e 0,00006 kg de $\mathrm{N}_{2} \mathrm{O}$; e para $1 \mathrm{GJ}$ de energia derivada de óleo diesel são emitidos 74,1 $\mathrm{kg} \mathrm{CO}_{2}, 0,003 \mathrm{~kg} \mathrm{CH}_{4}$ e 0,00006 kg N $\mathrm{N}_{2} \mathrm{O}$ (IPCC-NGGIP, 2019).

\section{2 Área de estudo}

O município de Balsas (Figura 1) possui 83.537 habitantes, área de 13.141,733 $\mathrm{Km}^{2}$ e densidade demográfica de 16,36 hab/ $\mathrm{Km}^{2}$. Do total da população residente, cerca de $49,8 \%$ é do sexo masculino e $50,2 \%$ do sexo feminino, $76,6 \%$ são

\footnotetext{
${ }^{1}$ GEEs: Gases do Efeito Estufa.
} 
alfabetizadas e 87,1\% residem na área urbana (IBGE, 2010).

Limita-se ao Norte com os municípios de São Raimundo das Mangabeiras e Fortaleza dos Nogueiras; ao Sul, com o município de Alto Paranaíba e o Estado do Pará; a Leste, com os municípios de Sambaíba, Tasso Fragoso e Alto Paranaíba e a Oeste, com os Municípios de Nova Colinas e Riachão (Brito E Feitosa, 2006).

No sul do Maranhão, os resultados da cadeia produtiva da soja são expressivos. Na safra de 2013/2014, a produção de grãos de soja atingiu 1,6 milhão de toneladas, a área plantada alcançou 580 mil hectares, e a produtividade média foi de 2.752 $\mathrm{kg} / \mathrm{ha}(\mathrm{CONAB}, 2015)$.

Entre 2000-2014, o crescimento da produção foi de 430\% e a da área plantada foi de 360\% (CONAB, 2015). Somente no município de Balsas, polo regional, a produção da soja cresceu de 152 mil toneladas, em 2000, para 457 mil toneladas, em 2014, o que coloca Balsas como terceiro maior município produtor de grãos de soja da região do MATOPIBA, perdendo apenas para Formosa do Rio Preto (BA) e São Desidério (BA), com quantidade produzida de soja em 2014, respectivamente, de 959 mil e de 720 mil toneladas (IBGE, 2015).

Figura 1: Mapa de Localização da área de estudo.
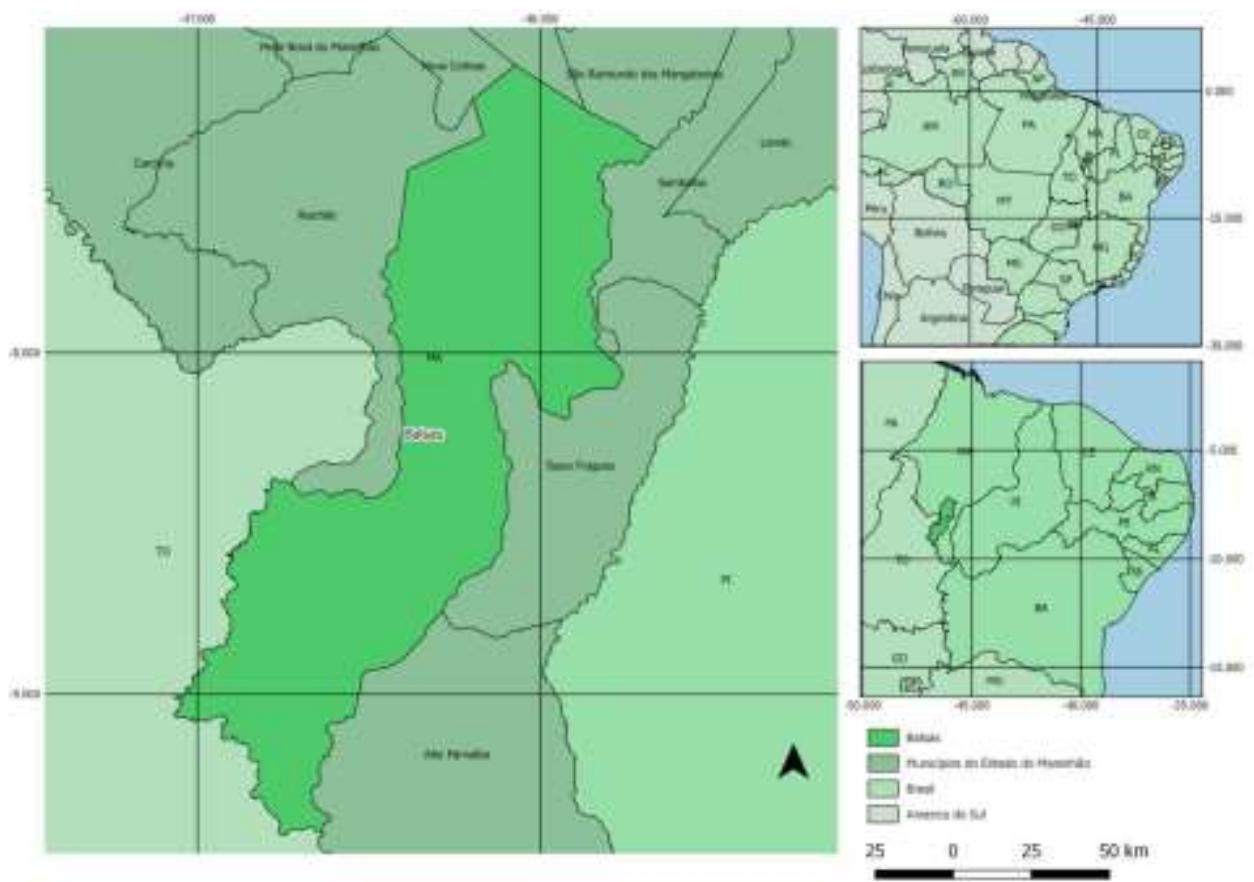

Fonte: Martins (2017).

\section{Resultados e Discussão}

Com base na descrição dos métodos detalhados para a análise do trabalho, elaborou-se mapas que mostram os principais pontos fixos de emissão de poluentes em relação às zonas/bairros específicos da cidade de Balsas/Ma. A Figura 2 mostra os bairros avaliados em relação ao município de Balsas, assim como os pontos de emissão para cada bairro. 
Figura 2: Delimitação poligonal total das áreas, por bairros, com pontos de emissão em relação ao município de Balsas.

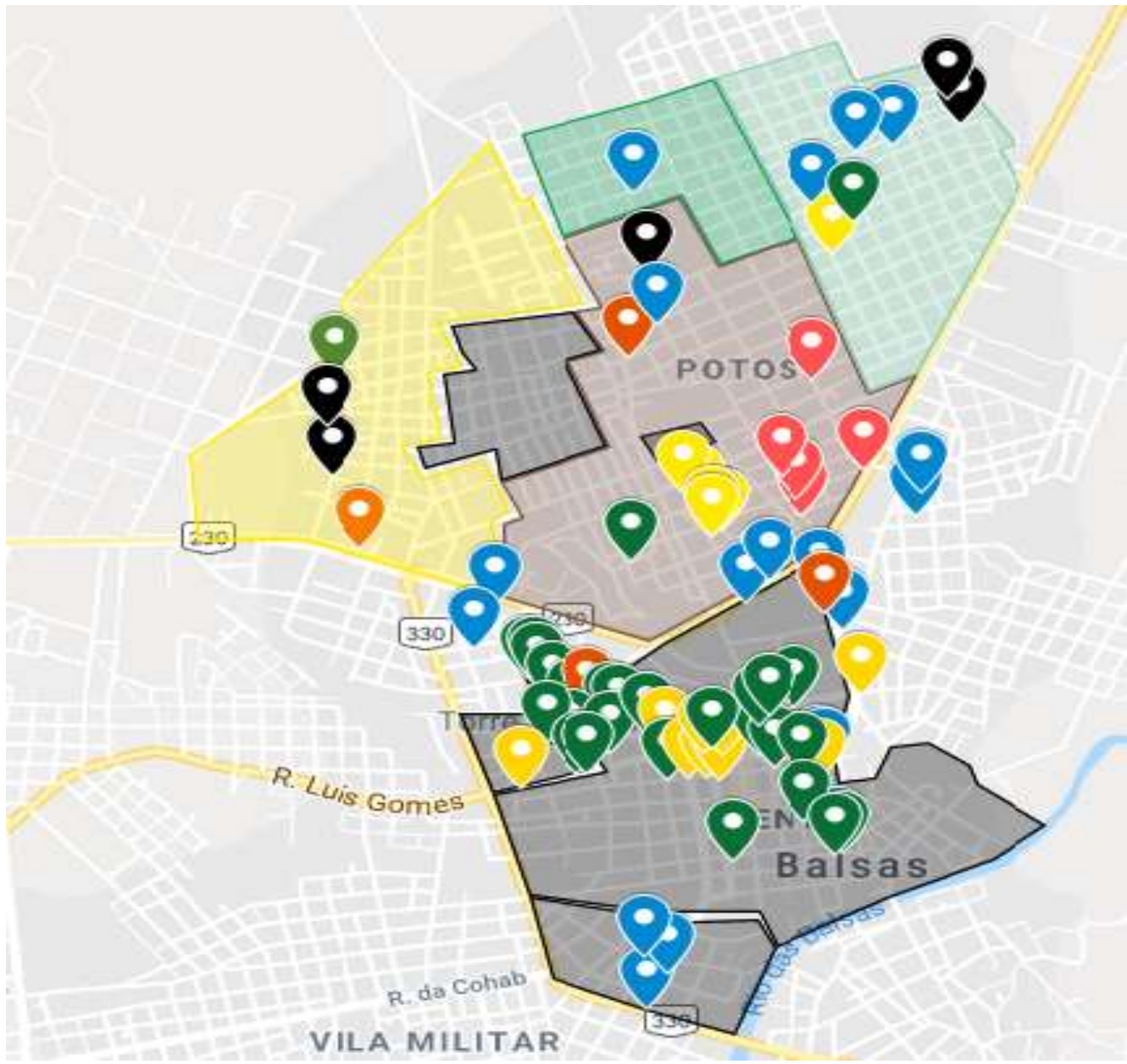

Fonte: Autores (2019).

A figura 2 apresenta os pontos de emissão em sua totalidade, visto a avaliação dos bairros que foram analisados. Os pontos que são destacados em verde são empreendimentos alimentícios gerais tais como pizzarias, bares, restaurantes e lanchonetes. Os pontos em amarelos são as padarias e espetinhos. Os azuis representam os comércios de nível pequeno a mediano. Os pontos de cor laranja apresentam os grandes atacados do município. Os de cores rosa, são as oficinas mecânicas tanto para carro como para moto, enquanto que os de cor preta são as partes da cidade com grande levantamento de partículas sólidas como marcenaria, depósitos de areia e indústrias beneficiadoras de arroz. A Tabela 1 a seguir apresenta a quantidade de pontos amostrados por cor assim como a totalidade avaliada no município de Balsas.

Tabela 1: Quantitativo de pontos amostrados por cor.

\begin{tabular}{l|l}
\hline Cor & Total amostrados \\
\hline Verde & 28 \\
\hline Amarelo & 15 \\
\hline Rosa & 5 \\
\hline Azul & 18 \\
\hline Preto & 5 \\
\hline Laranja & 4 \\
\hline Total & 70 \\
\hline
\end{tabular}

Fonte: Autores (2019). 
Figura 3: Delimitação poligonal de bairros específicos para análise.

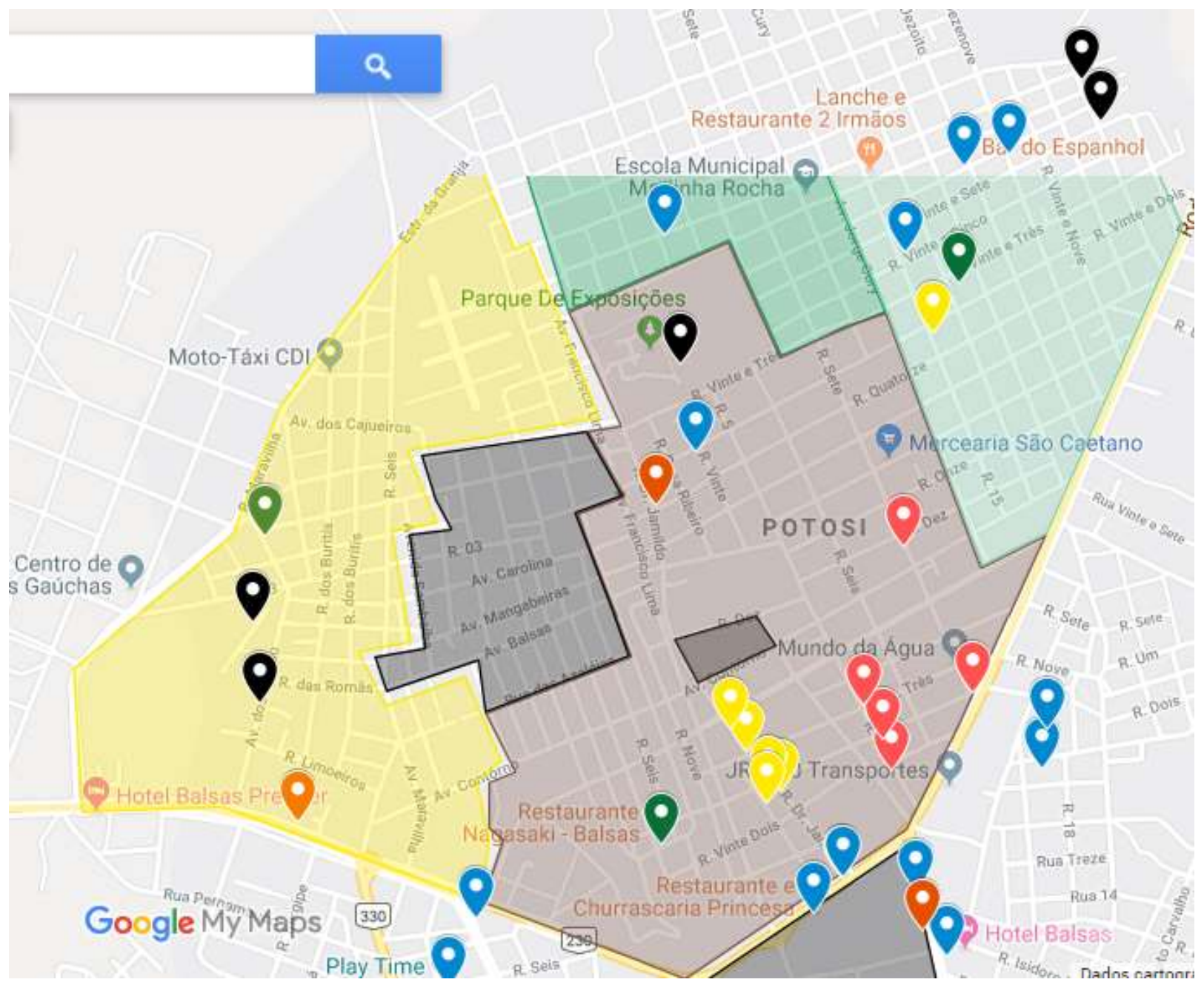

Fonte: Autores (2019).

A Figura 3 mostra a avaliação em relação a bairros específicos delimitados por polígonos e cores diferenciadas para melhor visualização das áreas que foram analisadas, deste modo:
Bairro CDI: Cor amarela;
Bairro Potosí: Marrom claro;
- Bairro São Francisco: Cor acinzentada;
- Bairro São Félix: Cor azul claro;
- Bairro São Luís: Cor verde claro;

Uma vez especificado a delimitação poligonal das áreas e suas respectivas cores de representação, dá-se início a avaliação dos pontos amostrados quanto a sua emissão e avaliação legislativa, desse modo:

\section{Para os Pontos de Cor Verde:}

Os pontos de cor de verde, como descrito anteriormente, referem-se aos estabelecimentos alimentícios e de consumo de bebidas como pizzarias, bares, restaurantes e lanchonetes. Para o Ministério do Meio Ambiente os padrões de qualidade do ar (PQAr) segundo publicação da Organização Mundial da Saúde (OMS) em 2005, variam de acordo com a abordagem adotada para balancear riscos à saúde, viabilidade técnica, considerações econômicas e vários outros fatores políticos e sociais, que por sua vez dependem, entre outras coisas, do nível de desenvolvimento e da capacidade nacional de gerenciar a qualidade do ar. 
As diretrizes recomendadas pela OMS levam em conta esta heterogeneidade e, em particular, reconhecem que, ao formularem políticas de qualidade do ar, os governos devem considerar cuidadosamente suas circunstâncias locais antes de adotarem os valores propostos como padrões nacionais. Para o caso desses pequenos estabelecimentos, não existe uma normativa ou quantificação para o valor que pode vim a ser gerado para os processos, pois de fato, esses tipos de ambiente não geram demasiados danos quanto a valores expressivos de emissão de poluentes ou dos tipos de poluentes que estão na classificação como sendo perigosos.

Contudo, uma observação deve ser mencionada. Geralmente nesses tipos estabelecimentos existe a queima da biomassa para o processo de assar carnes para o consumo dos clientes, essa queima, gera Material particulado, que, por sua vez, está contido na lista de poluentes atmosféricos. Locais como esse tendem a funcionar quase todos os dias da semana, e aqui entra um ponto interessante. Mesmo que um local não emita poluição em grande quantidade quando comparado a indústrias e conglomerados do meio, não significa que o mesmo não seja dado como descartado, pois algo é considerado como poluente se a sua concentração for maior do que o volume atmosférico de determinado local. Desse modo, estes locais podem ser pontos de importância devido ao fato de trabalharem todos os dias da semana, e sempre com produção de material particulado que é lançado na atmosfera. Em relação a quantidade, foram encontrados 28 pontos de emissão que detém essas características.

\section{Para os Pontos de Cor Amarela:}

Os pontos de cor amarela representam as padarias e espetinhos. Quando trata-se das padarias em virtude das chaminés que esse tipo de estabelecimento possui percebe-se que se olharmos para a fumaça que sai de uma chaminé, verá que em poucos dias do ano ela sobe verticalmente. Na maior parte das vezes ela se inclina, porque o ar ao redor da chaminé está em movimento. Mesmo quando parece haver apenas uma brisa próxima ao solo, nas camadas mais altas o vento pode ser bem mais forte. A poluição que sai das chaminés é levada pelo vento. Uma parte dela pode permanecer no ar durante uma semana ou mais, antes de se depositar no solo. Nesse período ela pode ter viajado muitos quilômetros. Mesmo um vento fraco de $16 \mathrm{~km} / \mathrm{h}$ poderia transportá-la para além de $1600 \mathrm{~km}$ em cinco dias.

Quanto mais a poluição permanece na atmosfera, mais a sua composição química se altera, transformando-se num complicado coquetel de poluentes que prejudica o meio ambiente. Mesmo não possuindo chaminés a fumaça que gerada por meio da queima da biomassa para assar as carnes nos espetinhos também passa por um processo semelhante.

Conforme a CETESB (2006), a descrição dada ao material particulado é que esse se constitui como sendo uma mistura de inúmeros compostos podendo estar tanto em um estado líquido como em um estado sólido. De uma maneira mais generalizada, esse tipo de material se encontra (como já mencionado), em forma conjunta, podendo ser encontrado em poluentes formados pela poeira ou fumaças além dos mais variados materiais sejam líquidos ou gasosos que possuem uma certa permanência, dentro de um intervalo de tempo, de se manterem em suspensão na atmosfera. Os veículos automotores, queima de biomassa (o que acontece para as padarias e espetinhos), ressuspensão de poeira do solo, entre outros, são alguns exemplos de fontes desse tipo de material. O material particulado pode também se formar na atmosfera a partir de gases como dióxido de enxofre $\left(\mathrm{SO}_{2}\right)$, óxidos de nitrogênio $\left(\mathrm{NO}_{\mathrm{x}}\right)$ e compostos orgânicos voláteis $(\mathrm{COVs})$, que são emitidos principalmente em atividades de combustão, transformando-se em partículas como resultado de reações químicas no ar. O tamanho das partículas está diretamente associado ao seu potencial para causar problemas à saúde, sendo que quanto menores maiores os efeitos provocados.

A fumaça que é emitida deste tipo de estabelecimento está associada ao material particulado suspenso na atmosfera proveniente dos processos de combustão. O método de determinação da fumaça é baseado na medida de refletância da luz que incide na poeira (coletada em um filtro), o que confere a este parâmetro a característica de estar diretamente relacionado ao teor de fuligem na atmosfera. 
Para os Pontos de Cor preta:

Os pontos de cor preta são os que representam os estabelecimentos como marcenarias, serralherias, indústrias beneficiadoras de arroz e depósito de areia. Esse tipo de local tende a gerar, além do material particulado, outras variantes tais como, Partículas Totais em Suspensão (PTS), Partículas Inaláveis $\left(\mathrm{MP}_{10}\right)$ e Partículas Inaláveis Finas $\left(\mathrm{MP}_{2,5}\right)$.

As Partículas Totais em Suspensão (PTS) podem ser definidas de maneira simplificada como aquelas cujo diâmetro aerodinâmico é menor ou igual a $50 \mu \mathrm{m}$. Uma parte destas partículas é inalável e pode causar problemas à saúde, outra parte pode afetar desfavoravelmente a qualidade de vida da população, interferindo nas condições estéticas do ambiente e prejudicando as atividades normais da comunidade (CETESB, 2006).

As Partículas Inaláveis ( $\left.\mathrm{MP}_{10}\right)$ podem ser definidas de maneira simplificada como aquelas cujo diâmetro aerodinâmico é menor ou igual a $10 \mu \mathrm{m}$. Dependendo da distribuição de tamanho na faixa de 0 a $10 \mu \mathrm{m}$, podem ficar retidas na parte superior do sistema respiratório ou penetrar mais profundamente, alcançando os alvéolos pulmonares. E por último as Partículas Inaláveis Finas $\left(\mathrm{MP}_{2,5}\right)$ podem ser definidas de maneira simplificada como aquelas cujo diâmetro aerodinâmico é menor ou igual a 2,5 $\mu \mathrm{m}$. Devido ao seu tamanho diminuto, penetram profundamente no sistema respiratório, podendo atingir os alvéolos pulmonares (CONAMA, 2019). Foram encontrados quatro (4) locais dentro dessa classificação em relação ao município.

Para os Pontos de Cor laranja:

Esta cor laranja representa os maiores centros de Atacado e Varejo do município. Em geral, para estes tipos de estabelecimentos existe uma maior aplicação da legislação voltada para redução de emissão de poluentes. No Geral, apenas 4 pontos foram marcados como sendo desse nível. Devido haver um maior rigor legislativo para empresas desse porte, as possíveis emissões como o dióxido de carbono por queima de resíduos é mais controlada, porém deve-se levar em consideração que estes mesmos locais possuem um maior volume quando comparados a terceiros, e obviamente (mesmo que de forma indireta) possuem uma maior taxa de emissão,

Para os Pontos de Cor azul:

São os pequenos comércios a medianos. Ao que foi observado não há algo em suas funções que possa ser considerado de fato como ponto de emissão de poluentes. Mas ocorre de sobremaneira a queima de resíduos, embalagens e outros desse meio principalmente nos bairros que não são tão próximos ao centro, como o CDI, Potosi, São Luís e São Félix, onde os donos dos comércios levam os materiais gerados para terrenos baldios e queimam, nesse processo tanto óxidos de nitrogênio como enxofre são gerados na combustão.

Para os Pontos de Cor rosa:

Sendo os esses os últimos de análise que estão dentro da zona urbana da cidade de Balsas, a cor representa as oficinas tanto de motos como de carros. O processo de soldagem com eletrodo revestido, na nomenclatura técnica MMA ou SMAW (Manual Metal Arc ou Shielded Metal Arc Weding), ainda é o processo de soldagem mais largamente utilizado. É o processo onde se utiliza um eletrodo consumível revestido com um fluxo para efetuar a solda. Uma corrente elétrica fornecida pelo equipamento de soldagem apropriado forma um arco elétrico entre o eletrodo consumível e a peça metálica, promovendo a união das partes. Durante a execução o fluxo que reveste o eletrodo se funde e se vaporiza.

A porção fundida passa a integrar o cordão de solda e a escória resultante. Já a parte que se vaporiza forma uma atmosfera que protege a poça de fusão dos efeitos nocivos do oxigênio do ar. O processo de soldagem com eletrodo revestido é dominante sobre os demais, especialmente nas áreas de serralheria, montagens industriais, e manutenção e reparo, embora os processos semi-automáticos estejam crescendo em utilização. 
Research, Society and Development, v. 10, n. 16, e227101619506, 2021

(CC BY 4.0) | ISSN 2525-3409 | DOI: http://dx.doi.org/10.33448/rsd-v10i16.19506

Os materiais mais comumente soldados por este processo são os aços carbono, aços liga e aços inoxidáveis. Alguns materiais não ferrosos como Alumínio, Níquel e Cobre também podem ser soldados por este processo. Obviamente durante a combustão, há a liberação de gases com base nos materiais, e no que foram observados, as oficinas do município não seguem nenhuma legislação quanto ao uso de possíveis filtros de ar para uma possível redução desses gases na atmosfera, assim como para a maioria dos pontos amostrados.

As figuras 4, 5, 6 e 7 mostradas a seguir, mostram as imagens de satélite da região de Balsas, enfatizando não somente o centro urbano, mas todos os arredores da região que compreendem em sua maioria as fazendas do município de Balsas.

Figura 4: Imagem de satélite da cidade de Balsas da região urbana centralizada.

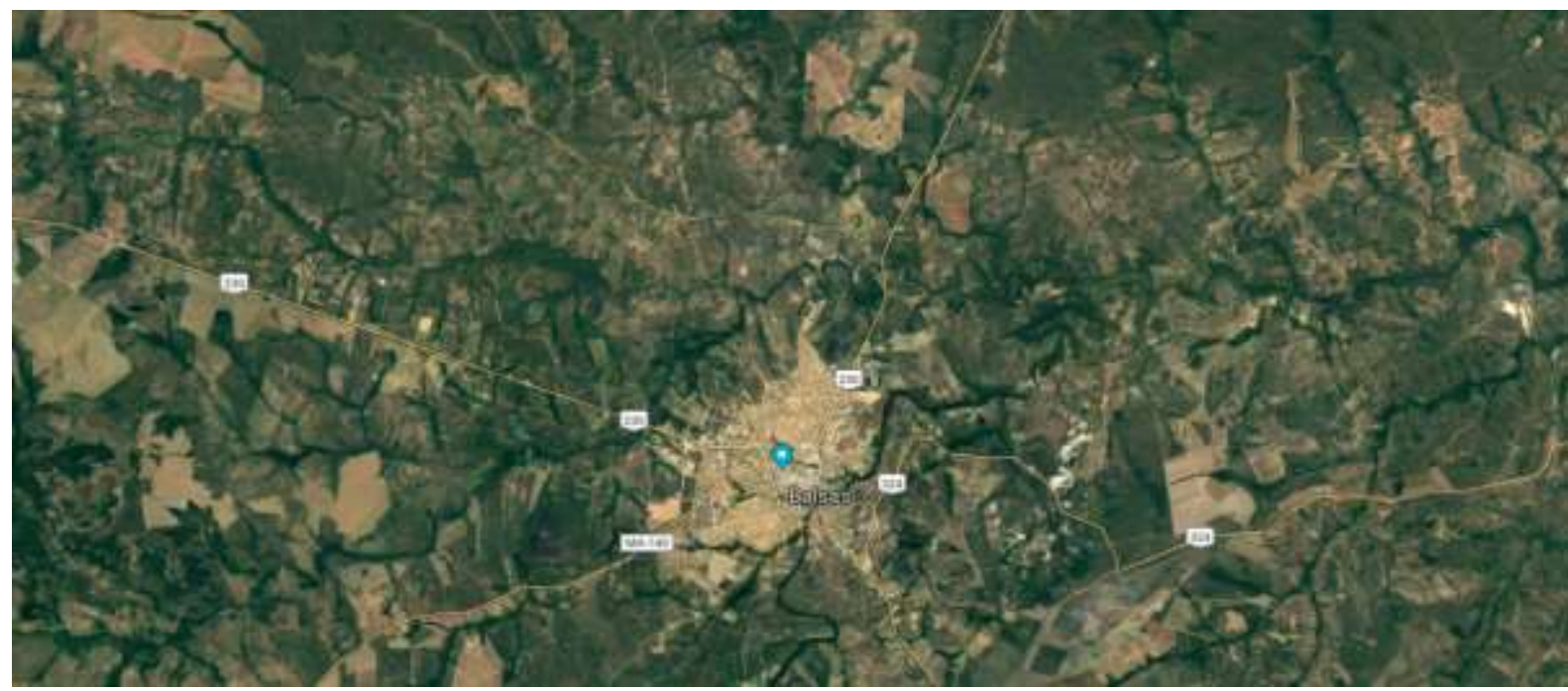

Fonte: GEW (2019).

A Figura 4 mostra a cidade de Balsas mais centralizada, mas já é possível perceber que próximo a esta região já existem locais para agricultura bem demarcados (identificados por essas zonas mais claras) e que sugerem tanto desmatamento como agricultura e que, independentemente do tipo de comodities ali plantado, é local de aplicação de agrotóxicos que também é outro tipo de poluente atmosférico.

Figura 5: Imagem de Satélite da região norte de Balsas com sua delimitação.

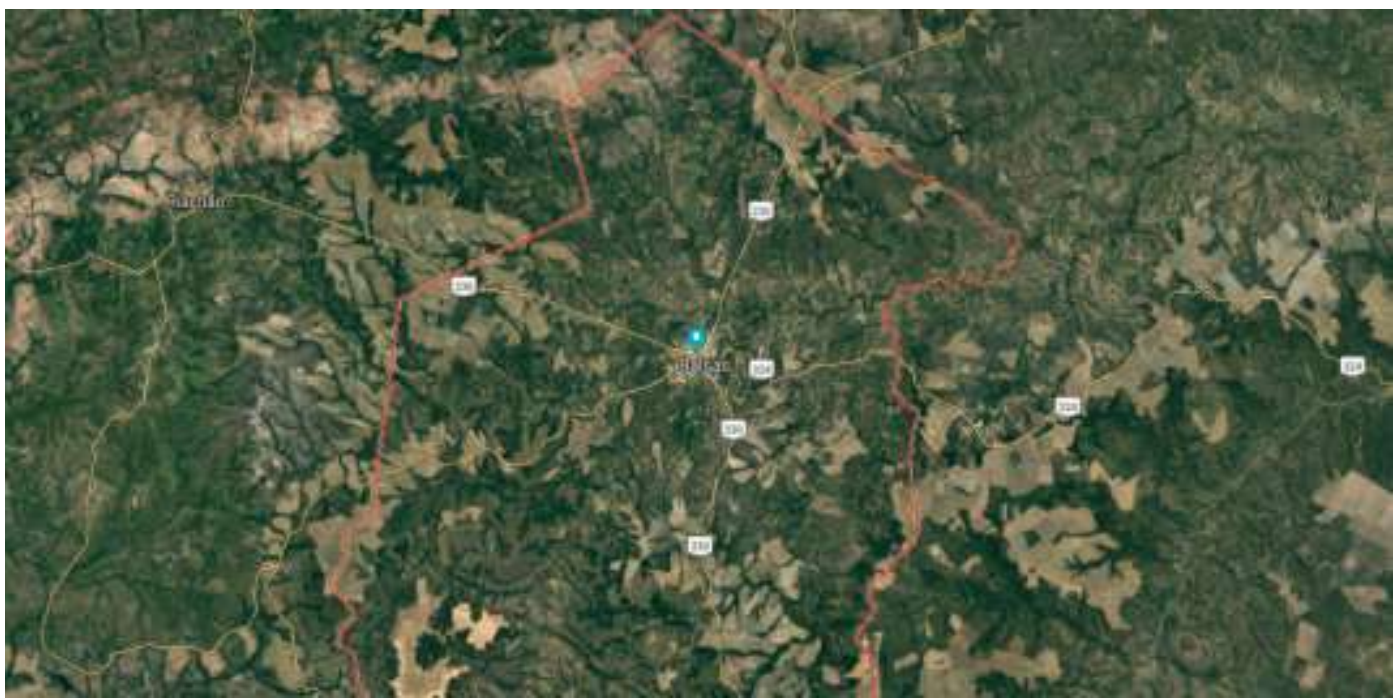

Fonte: GEW (2019). 
Research, Society and Development, v. 10, n. 16, e227101619506, 2021

(CC BY 4.0) | ISSN 2525-3409 | DOI: http://dx.doi.org/10.33448/rsd-v10i16.19506

Figura 6: Imagem de Satélite da Região sul do município de Balsas delimitada por suas fronteiras municipais.

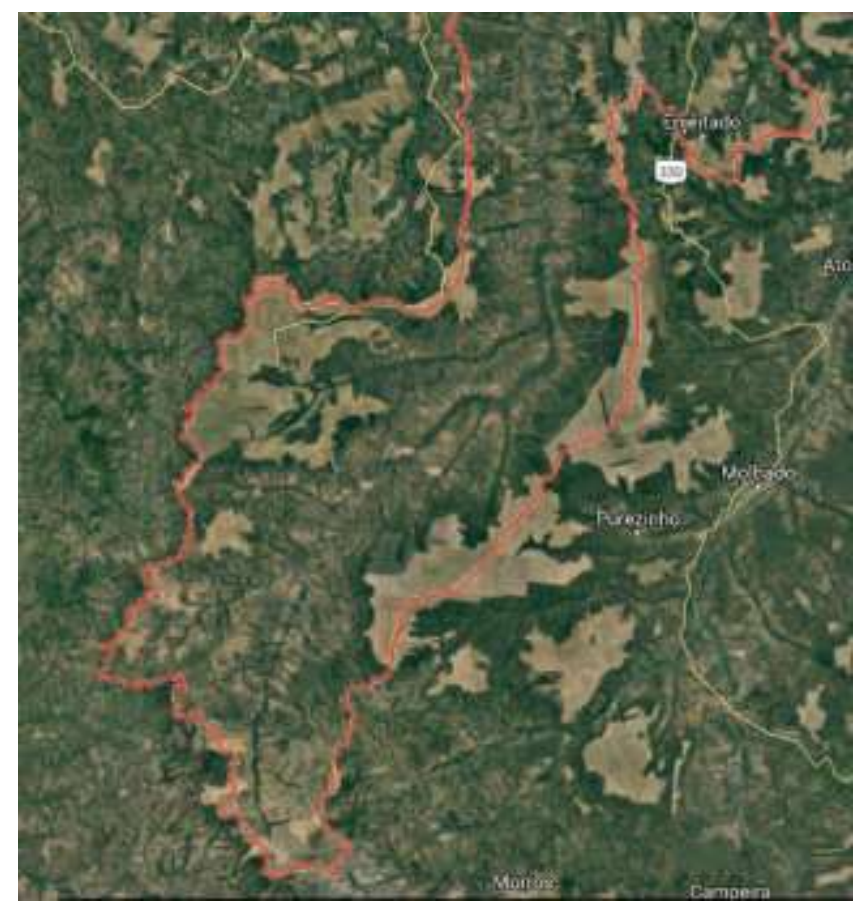

Fonte: GEW (2019).

As figuras 5 e 6 mostram o município de Balsas de modo mais centralizador, ou para melhor visualização quanto a zonas que servem para agricultura, com melhor enfoque a figura $6 \mathrm{com}$ enfoque para a parte norte e a Figura 6 para a parte sul da região do município.

Figura 7: Imagem de Satélite mostrando a cidade de Balsas em toda sua totalidade,

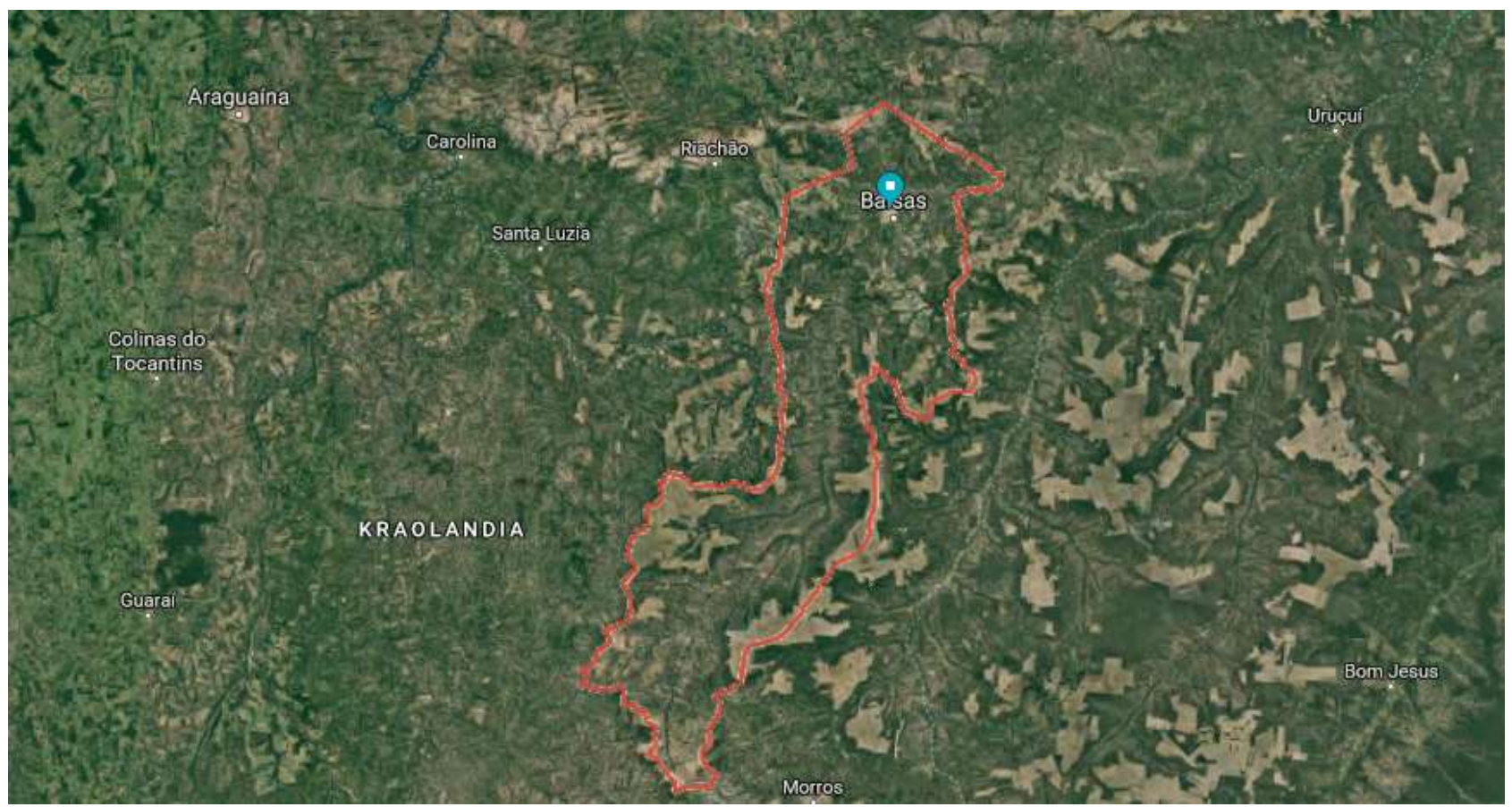

Fonte: GEW (2019).

A Figura 7, por sua vez, mostra toda a região de Balsas vista por satélite e delimitada por um contorno de cor vermelho. 
Para a produção de cana-de-açúcar, estima-se que, durante todo o processo, que envolve plantio da cana, manejo da cultura, colheita e produção do etanol, são emitidos 20,442 kg de CH4, 1,996 kg de N2O e 1.227,5 kg de CO2, dados por hectare. Logo, tem-se em Balsas, emissões anuais de 327,072 kg de CH4, 31,936 kg de N2O e $19.640 \mathrm{~kg}$ de CO2.

Já para a cultura da soja, os dados são mais significativos quando se leva em conta os próprios processos do cultivo e a quantidade de área plantada na região emissões de gases do efeito estufa associadas à cultura surgem do uso de adubos (P, K e micronutrientes) e corretivos de solo, herbicidas e pesticidas, e as operações mecânicas para plantio, tratos culturais, colheita e armazenamento de grãos (Soares et al, 2007).

Considera-se que são utilizados $170 \mathrm{~kg}$ de fertilizantes ha-1, onde estima-se que de 7,32 kg de fertilizantes, 3,10 kg são perdidos na forma de emissão atmosférica, conforme Júnior, Gimenes e Ugaya (2013), ou seja, 42,35\%. Já para a emissão proveniente do uso de combustíveis do maquinário, envolvendo todas as etapas, estima-se 920 kg.ha-1 por ano. Logo, tem-se para a cidade de Balsas, $31.814 .480 \mathrm{~kg}$ de fertilizante utilizados, destes, $13.474 .432,3 \mathrm{~kg}$ são emitidos na forma de NO2 para a atmosfera, e 1.721.172.480 kg de $\mathrm{CO} 2$ proveniente do uso de combustível fóssil no maquinário, dados concordados com os valores genéricos obtidos no trabalho de Soares et al (2007) onde considera-se que nos processos de produção da soja consumese cerca de 11GJ ha-1, equivalente a 808,5 kg CO2 ha-1 que são emitidos para a atmosfera ${ }^{2}$.

Para a cultura do milho, considera-se a aplicação de $80 \mathrm{~kg}$ de nitrogênio $(\mathrm{N})$ ha-1 por grandes produtores, porém, temse que pequenos produtores não utilizam essa prática, logo, estima-se uma quantidade de $30 \mathrm{~kg} \mathrm{~N}$ ha-1de fertilizantes, o que implica em emissão de 0,8 kg N-N2O ha-1 (Soares et al, 2007). Tratando as estimativas com os dados disponíveis da região de Balsas, tem-se, 81.953,6 kg de N-N2O ha-1 anualmente. Para emissões de CO2, também se considera a energia envolvida ao longo de todos os processos, tendo uma estimativa, segundo Soares et al. (2009) que leva em consideração, além dos processos, as diferenças entre as formas de cultivo de grandes e pequenos produtores, tem-se produção de cerca de $966 \mathrm{~kg} \mathrm{CO} 2 \mathrm{ha}-1$, anualmente.

Cabe ressaltar ainda que, segundo dados do SEEG (2017), o Brasil, sendo um dos maiores produtores de alimentos do mundo, possui dados de agropecuária com emissões de 425 MtCO2e (milhões de toneladas de CO2 equivalente) em 2015, ou seja, quase 1/3 das emissões nacionais, e as análises revelam que em 40 anos a emissão de gases do efeito estufa aumentaram cerca de 165\%. Na região de Balsas, segundo dados do IBGE (2017), tem-se 872 estabelecimentos agropecuários de criação bovina, com aproximadamente 44.778 cabeças; e 411 estabelecimentos agropecuários de criação suína, com aproximadamente 24.951 cabeças; e demais tipos de rebanho distribuídos em uma área de 76.681,261 ha.

Segundo Soares (2009), ocorrendo por meio da deposição de excreções dos animais e aplicação de fertilizantes no pasto, estima-se que são emitidos 0,239 kg N2O ha-1 anualmente, o que seria 18.326,8 kg N2O ha-1 ano-1 emitidos na região de Balsas, desconsiderando processos de preparo do solo, transporte de animais e manutenção do pasto que demandam do consumo de energia e emitem gases como o $\mathrm{CO} 2$.

\section{Considerações Finais}

Com base no levantamento dos dados obtidos e da averiguação com a literatura temos que:

- $\quad$ A cidade de Balsas ainda encontra-se dentro de um padrão moderado quanto ao quantitativo dos dados avaliados, isso porque a região urbana compreende menos de $20 \%$ (estimativa) do total da área em estudo, porém é necessário controle, pois a tendência das estimativas é sempre aumentar, visto que ainda não existe um controle para tais emissões;

- $\quad$ O principal problema de Balsas quanto a poluição do ar não se concentra apenas no perímetro do urbano, mas principalmente nas fazendas, e mais especificamente em certos períodos do ano onde existe o processo de queima para

\footnotetext{
${ }^{2}$ Observação: $1 \mathrm{GJ}$ de energia de petróleo é equivalente $73,5 \mathrm{~kg} \mathrm{CO}_{2}$ eq.
} 
mineralização e recolocação dos nutrientes do solo para novos plantios, e isso geralmente ocorre na época mais seca do ano, e faz com que inúmeras pessoas, como constatado por pessoas da área da saúde, tenham problemas respiratórios;

- $\quad$ Tratando das estimativas com os dados disponíveis da região de Balsas, tem-se, 81.953,6 kg de N-N2O ha-1 e produção de cerca de 966 kg CO2 ha-1, anualmente na região, isso para a produção;

Diante disso, o presente trabalho mostrou que mesmo em um perfil dado como moderado, a cidade possui tendência a ter índices que podem se elevar com o tempo, por alguns motivos, tais como:

- $\quad$ Falta de fiscalização por parte de órgãos ambientais;

- $\quad$ Falta de Conscientização por parte da população, que ignora todos os sinais de que os danos gerados pela emissão de poluentes não afetam apenas o meio ambiente, mas todos os seres que vivem naquele determinado meio, e isto inclui o ser humano.

\section{Referências}

Berni, M. D., \& Bajay, S. V. Implicações Energéticas e Ambientais da Eliminação das Queimadas de Canaviais. In: III Congresso Brasileiro de Planejamento Energético, 1998, Campinas-SP. Anais.pg 175-178.

Brito, L. C, \& Feitosa, A. C. A Influência Da Erosão Hídrica Na Formação Dos Solos Em Áreas Agrícolas Do Município De Balsas-Ma. Simpósio Nacional de Geomorfologia. Setembro de 2006.

Bueno, M. Os desafios do Maranhão: prosperidade no cerrado. Agroanalysis: Revista de Agronegócio da FGV.11-18, 2001.

Cançado, J. E. D. et al. Repercussões clínicas da exposição à poluição atmosférica. Jornal Brasileiro de Pneumologia, 32, S5-S11.

CEPEA/ESALQ - Centro de Estudos Avançados em Economia Aplicada da Escola Superior de Agricultura "Luiz de Queiroz". PIB do Agronegócio BRASIL. São Paulo, setembro 2016.

Cesar, G. C. A., Nascimento, C. F. L., \& Carvalho, A. J. Associação entre exposição ao material particulado e internações por doenças respiratórias em crianças. Revista de Saúde Pública, 47(6), 1209-12, 2013.

CETES (Companhia Ambiental do Estado de São Paulo). Informações básicas da qualidade do ar. 2019. < https://cetesb.sp.gov.br/ar/ >

CETESB - Companhia de Tecnologia de Saneamento Ambiental. Relatório de qualidade do ar no Estado de São Paulo. São Paulo, 2006.

CETESB. Relatório de qualidade das águas interiores no Estado de São Paulo 2005. CETESB, 2006.

CONAB- Companhia Nacional de Abastecimento. Perspectivas para a Agropecuária. Volume 3-Safra 2015/2016. Brasília. 2015.

Conselho Nacional do Meio Ambiente (CONAMA). <www.mma.gov.br/conama>,

GEW. Google Earth Website. https://www.google.com/earth/.

Gonçalves, T. L. F. et al. Modelagem dos processos de remoção sulfato e dióxido de enxofre presente no particulado em diferentes localidades da região metropolitana de São Paulo. Revista brasileira de Geofísica, 28, 109-19.

Gouveia, N. et al. Hospitalizações por causas respiratórias e cardiovasculares associadas à contaminação atmosférica no Município de São Paulo. Cadernos de Saúde Pública, 22(12), 2669-77, 2006.

IBGE - Institudo Brasileiro de Geografia e Estatística. Produção Agrícola - Lavoura Temporária: cidade de Balsas-Ma, 2017.

IBGE- Instituto Brasileiro de Geografia e Estatística. Produção Agrícola. 2015.

IBGE, Levantamento Sistemático da Produção Agrícola, Pesquisa Mensal de Previsão e Acompanhamento de Safras Agrícolas no Ano Cívil, fevereiro, 2016.

IBGE, Levantamento Sistemático da Produção Agrícola, Pesquisa Mensal de Previsão e Acompanhamento de Safras Agrícolas no Ano Cívil, dezembro, 2015.

IBGE-Instituto Brasileiro de Geografia e Estatística. Atlas Digital Brasil 1 po 1. Censo de 2010.

IPCC-NGGIP. Guidlines for national greenhouse gas inventories: 2006. <http://www.ipcc- nggi.iges.or.jp/public/2006gl>.

Junior, J. T., Gimenes, M. L., \& Ugaya, C. M. (2013). Estimativa dos recursos necessários e potenciais emissões poluentes na produção de soja no Paraná: em busca de uma produção mais sustentável. IX Fórum Ambiental da Alta Paulista, 9(7), 110-121.

Mario, M. P. J. Poluição atmosférica como condicionante no processo de ocupação do espaço urbano: Análise na cidade de Porto Alegre, RS. 2012. Dissertação (Mestrado em Planejamento Urbano e Industrial) - Universidade Federal do Rio Grande do Sul. 2012. 
Research, Society and Development, v. 10, n. 16, e227101619506, 2021

(CC BY 4.0) | ISSN 2525-3409 | DOI: http://dx.doi.org/10.33448/rsd-v10i16.19506

Martins, M. V. E. A segurança na aplicação de agrotóxicos na região de Balsas/MA. Projeto de Pesquisa para o Trabalho de Contextualização e Integração Curricular I. Universidade Federal do Maranhão- Campus Balsas. Junho de 2017.

Nascimento, L. F. C., \& Francisco, J. B. Material particulado e internação hospitalar por hipertensão arterial em uma cidade brasileira de porte médio. Cadernos de Saúde Pública, 29(8), 1565-71, 2013.

Portal IMESC, Nota de Conjuntura Mensal - Produção Agrícola Maranhense, <http://http://www.imesc.ma.gov.br/ components/com_booklibrary/ebooks/Nota\%20de\%20Agricultura\%20-\%20Outubro.pdf >

SEEG - Sistema de Estimativas de Emissões de Gases de Efeito Estufa. Emissões do Setor de Agropecuária. 2017. Disponível em: http://seeg.eco.br/. Acesso em: maio de 2019.

Soares, L. H. B., Muniz, L. C., Figueiredo, R. S., Alves, B. J. R., Boddey, R. M., Urquiaga, S., Madari, B. E., Machado, P. L. O. A. Balanço energético de um sistema integrado lavoura- pecuária no Cerrado. Embrapa Agrobiologia, 2007. 28 p

Soares, L. H., Alves, B. J., Urquiaga, S., \& Boddey, R. M. Mitigação das emissões de gases de efeito estufa pelo uso de Etanol da Cana-de-açúcar produzida no Brasil. Circular Técnica, Embrapa, 2009, 